\title{
Business Intelligence And Information Systems: Enhancing Student Knowledge In Database Courses
}

David H. Olsen, Utah State University, USA

Pam-Dupin Bryant, Utah State University, USA

\begin{abstract}
Companies are increasingly relying on business intelligence (BI) for decision making. However, integration of BI into university business courses has not kept pace with market needs. The purpose of this paper is to outline an innovative business intelligence teaching module for management information systems (MIS) education. The module was designed to highlight the basic principles of business intelligence as well as provide an applied experience with Microsoft Visual Studio using the Analysis Services and Reporting framework. This teaching module seeks to provide Information Systems students a relevant introduction to BI, providing a springboard to expand BI knowledge and prepare students for success in the business world.
\end{abstract}

Keywords: Business Intelligence; Business Analytics; Database Warehouse; Database Analytics; Management Information Systems Teaching; Instructional Strategies; Teaching/Learning Methods

\section{INTRODUCTION}

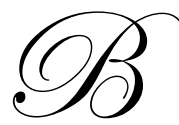

usiness intelligence (BI) has been defined as computer-based techniques used in spotting, digging-out, and analyzing business data, such as sales revenue by products and/or departments or associated costs and incomes (Business Intelligence, 2011). BI practices continue to evolve and provide businesses in many sectors with increasingly powerful tools and information for decision making. The vast amount of information available to companies needs to be harnessed and interpreted - "through BI initiatives, businesses are gaining insights from the growing volumes of transaction, product, inventory, customer, competitor, and industry data generated by enterprise-wide applications" (Chen, Chiang, \& Storey, 2010, p. 201). Companies ranging from IBM to the United States Postal Service have recorded measured improvements to business processes and decision making by implementing BI technologies (IBM, 2009; Laursen \& Thorlund, 2010; Morris, 2002; and Turban, Sharda, Dursun, \& King, 2010).

As $\mathrm{BI}$ is becoming more active in industry, more and more money is being allocated to BI projects, even in hard economic times. Two high profile surveys ranked BI as a top priority among Chief Information Officers (CIOs) (Gartner, 2006, and IBM 2009). A recent survey of more than 2,500 worldwide CIOs identified business intelligence/analytics as the top strategy for enhancing competitiveness - $86 \%$ of respondents had plans to use BI within five years (IBM, 2009).

Given this information, educators and business leaders alike argue that today's business graduates (and especially MIS graduates) must be exposed to BI concepts and practices during their course of study (Sircar, 2009; Conway \& Vasseur, 2009; Watson, 2008, and Watson \& Wixom, 2007). Watson (2008) suggests business schools need to alter what they teach in order to prepare graduates for a changing business landscape. Business schools have been slow to adopt BI courses and emphases (Sircar, 2009; Watson, 2008; Watson \& Wixom, 2007, and Wixom, 2010). Watson (2008) claims graduates must have some exposure to both BI concepts and technologies. Watson is not alone in this call. Conway and Vasseur (2009) feel current business programs do not provide adequate exposure to BI solutions to support planning, reporting, and analytics. Sircar (2009) suggests there is an urgent need for 
business schools to offer "curricula to address the demand for adequately qualified graduates" in the area of business intelligence/business analytics (p. 299).

While BI teaching is gaining some ground in academia, some educators feel "BI is still not mature enough or covered as well as other topics or areas in IS" and business and IS degrees need to focus more on BI as a utility in "areas like marketing, finance [and] insurance" (Wixom, 2010, p. 6). Many MIS degrees still lack focused applications of BI principles. Wixom (2010) suggests there is still more work to be done to develop pedagogy and high quality technology to support BI initiatives in the curriculum.

To enhance the database and business intelligence knowledge of MIS graduates, a business intelligence teaching module was developed, tested, and successfully applied in various upper division university database courses. The purpose of this paper is to outline this innovative Business Intelligence Teaching Module for information systems education. This module is based on a well respected theory of learning and grounded in current $\mathrm{BI}$ and database literature. The module was designed to highlight the basic principles of business intelligence as well as provide an applied experience with Microsoft Visual Studio using the Analysis Services and Reporting framework. This teaching module seeks to provide information systems students a relevant introduction to BI, providing a springboard to expand BI knowledge and prepare students for success in the business world.

Four major objectives provide a framework for this paper, including: 1) highlight relevant literature and theoretical underpinnings of the teaching module, 2) outline the methods and educational model employed, 3) describe the teaching module and share innovative ideas for implementing BI into database courses, and 4) provide concluding remarks and suggestions for future research and practice. This paper seeks to demonstrate the importance of integrating business intelligence learning objectives into university business curricula, specifically database coursework. The teaching module identified in this paper should prove helpful to information systems educators who seek to provide a rigorous, practical, and relevant business intelligence experience in their courses.

\section{LITERATURE REVIEW}

Business intelligence (BI) has been used as "an umbrella term to describe concepts and methods to improve business decision making by using fact-based support systems" including underlying tools, architectures, applications, databases, and methodologies (Chen et al., 2010, p. 201). Sircar (2009) notes the terms business intelligence (BI) and business analytics (BA) are often used synonymously; BI being the preferred term used by information technology professionals and BA more often used by the business community. BI will be used in this paper as an overarching term to describe $\mathrm{BI} / \mathrm{BA}$ objectives that provide business professionals the ability to easily access, interact with, manipulate, and transform large amounts of diverse data (Chen et al., 2010, and Turban, et al., 2010).

Watson and Wixom (2007) state "BI is emerging as a key enabler for increasing value and performance ... the future of business intelligence is bright" (p. 28). BI will continue to provide businesses with relevant and key information for decision making. IBM, 3M, and SAP are among many companies increasing their BI investments as other companies turn to dashboards and scorecards for improving business metrics and decision making (Watson \& Wixom, 2007). Data warehousing is considered the foundation of BI and more companies are investing in data collection, extraction, and analysis technologies (Chen, et al., 2010, and Turban et al., 2008). 3M justified a multimillion-dollar investment in a data warehouse platform due to savings from data mart consolidation. Inmon, Strauss, and Neushloss (2008) suggest data warehousing and BI have greatly enhanced business processes, i.e. frequent flyer programs, credit card fraud analysis, inventory management, and customer profiles.

Companies such as Novo Nordisk, Brother International, and the United States Postal Service (USPS) have greatly improved their reporting and key performance indicator metrics by implementing BI strategies (Morris, 2002). Healthcare provider Novo Nordisk has defined key performance indicators (KPIs) and implemented company-wide access to performance metrics and data, thereby enabling more informed decision making. Brother International implemented business analytic tools to support customer service representatives, resulting in savings of half a million dollars per year and a 32\% return on investment (ROI). The USPS boosted the performance of its retail outlets by installing a Retail Data Mart to extract data from a point of sale source system. This system has 
provided USPS with the ability to drill down to specifics on regions and even individual outlets, resulting in a $1,377 \%$ ROI. Laursen and Thorlund (2010) suggest "by now, it's an acknowledged fact that all the money that is invested is returned many-fold when BA [and BI] solutions are implemented and executed in the right way" (p. xiv).

BI has enabled the Richmond Virginia police department to nearly "predict" when and where crimes will occur and helped allocate resources accordingly (Smalltree, 2007). Shift supervisors have access to detailed information at the beginning of their shift as well as real time alerts from the system when a crime pattern is detected. BI tools have enabled the police department to be proactive rather than reactive in fighting crime. Internationally, Ming Ya Insurance in China has found benefit by implementing business intelligence systems (Xu, 2005). As the life insurance industry in China faces great challenges during a time of change, Ming Ya has used data mining, data warehousing, and meta databases to help determine the average amount customers are willing to pay for insurance consulting, as well as reduce the number of sales visits required before closing a sale. Euro Disney uses business intelligence to optimize the distribution of staff and avoid amusement park overcrowding (Laursen \& Thorlund, 2010). Along with the aforementioned examples countless organizations utilize BI to enhance business practices.

Parallel to the growth in business and industry, academic research related to business intelligence has recently grown in popularity. Numerous refereed journals, symposiums, and research conferences are dedicated to business intelligence and analytics. A review of literature over a 10 year period (1997-2006) found 167 articles closely related to BI in ten leading information systems journals (Jourdan, Rainer, \& Marshall, 2008). Plus, within the last 5 years even more high-quality BI/BA articles have been published in quality IS journals and the research stream is projected to continue. An upcoming special issue of MIS Quarterly, a premier journal in the field, will be dedicated solely to research on business intelligence (Chen et al., 2010). Jourdan et al. (2008) note an increasing trend in the number of BI related articles published in leading journals.

While BI is becoming more prevalent in day to day business practice and the body of BI literature is growing, it seems obvious BI would be fundamental to higher education business curricula. Yet, business schools have been slow to integrate BI (Sircar, 2009; Watson, 2008; Watson \& Wixom, 2007, and Wixom, 2010). Sircar (2009) highlights BI shortcomings in the business curriculum, suggesting there is a "mismatch between teaching, research, and practical relevance (not keeping up with developments in industry)" (p. 290). Conway and Vasseur (2009) believe current business programs do not provide adequate exposure to BI solutions to support planning, reporting, and analytics. There is an urgent need for business schools to offer curricula in the area of business intelligence and business analytics to meet the demand for qualified graduates who have BI knowledge and skills (Sircar, 2009). Watson (2008) claims graduates must have some exposure to both BI concepts and technologies. Many MIS degrees still lack focused applications of BI principles.

The key success factor for any enterprise is making sense of and harnessing the massive amounts of information flowing in and across the business (Ranjan, 2008). Given the increasing emphasis on BI in many business sectors, it follows that MIS graduates understand and apply at least basic BI principles if they are to use these principles to benefit business industries. Sircar (2009) argues one reason BI has been overlooked in the business curriculum is the continuing trend of faculty to focus on rigor at the expense of practical relevance. Business faculty are encouraged to break this trend and find creative methods to integrate rigorous and relevant BI learning objectives into university business courses.

\section{METHODS}

The business intelligence teaching module outlined in this paper was designed to be a hands-on, business relevant approach to reinforce key learning principles related to BI and databases.

The module was developed as a stand-alone activity that can be employed in any college level database course. The module was originally designed to be taught during one or two 75 minute class periods but could easily be adapted to shorter or longer time periods. Students will ideally have prior knowledge of conventional relational database principles. The teaching module has been tested and successfully applied in various upper division university database courses. However, information systems educators should modify and apply this module based on the needs of their students, their individual teaching preferences, and the course learning objectives. 
The content of the business intelligence module utilizes Gagne's Nine Events of Instruction as a learning framework (Gagne, Briggs, \& Wager, 1992). Gagne's Nine Events of Instruction is a well respected, systematic approach to teaching and is often employed as a tool for training and developing instructional strategies in business and technology related fields (IEEE, 2011; Liu, 2008; Reisslein, Seeling, \& Reisslein, 2005, and Zhu \& St. Amant, 2010). The instructional flow of this business intelligence module follows Gagne's nine events (see Figure 1). The module introduces students to the basic principles of business intelligence and teaches them how to use the Analysis Services and Reporting framework in Microsoft Visual Studio. The alignment of the business intelligence module with Gagne's Nine Events of Instruction, provides an educational environment in which learning and retention are enhanced. The events of instruction are listed below.

\section{Gagne's Nine Events of Instruction}

1. Gain Attention

2. Inform Learner of Objectives

3. Stimulate Recall of Prior Learning

4. Present Stimulus Material

5. Provide Learner Guidance

6. Elicit Performance

7. Provide Feedback

8. Assess Performance

9. Enhance Retention and Transfer

\section{MODULE CONTENT DESCRIPTION}

Following Gagne's Nine Events of Instruction (Gagne et al., 1992), this business intelligence module design includes a presentation of the learning objectives, the learning content, and practice activities with feedback and review of the learning content. All the components of the BI module are instructionally aligned with the learning objectives. The module was designed to introduce students to BI and help them understand the need for BI in today's business climate.

This BI teaching module introduces the difference between relational databases and a data warehouse, as well as dimensional modeling concepts. Using Microsoft Visual Studio, the Analysis and Reporting Services framework, and the robust sample AdventureWorks database, students are then instructed how to build, deploy, and glean data from a data cube. By providing this opportunity for students to learn BI concepts and practices, students can gain powerful tools to supplement their knowledge and skills.

The following section outlines each of the nine events of instruction used to highlight the basic principles of business intelligence and provide an applied experience with Microsoft Visual Studio using the Analysis Services and Reporting framework. Figure 1 shows each step in Gagne's Nine Events of Instruction along with the associated teaching strategy for the business intelligence teaching module. 


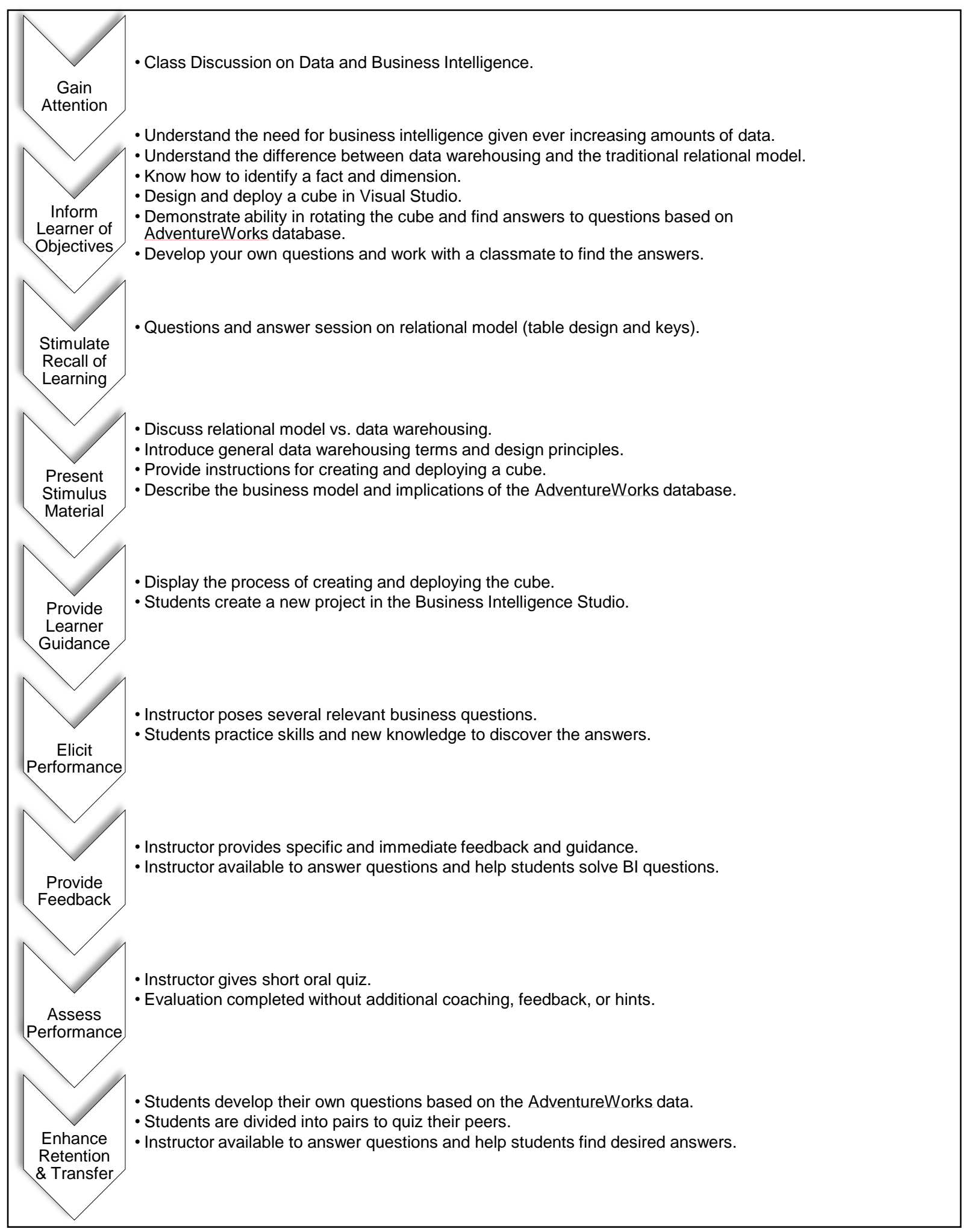

Figure 1: Business Intelligence Teaching Module 


\section{Gain Attention}

The instructor should conduct a short discussion (approximately XX minutes) surrounding the increasing amounts of data in today's world and how BI can help distill this data and provide real value. Content for this discussion can be found online, in course textbooks, and/or from myriad references identified in this manuscript. Current and startling material related to the topic should be used (as per the instructor's preference) to gain student attention.

\section{Inform Learner of Objectives}

After the instructor has gained student attention with a short discussion on business intelligence, the instructor should introduce the learning objectives. The learning objectives should be highlighted in an easy to read format (e.g. slide show) and also posted on the course learning management system (LMS) for easy retrieval and student access.

Students should be informed of the following objectives:

- $\quad$ Understand the need for business intelligence given ever increasing amounts of data.

- $\quad$ Understand the difference between data warehousing and the traditional relational model.

- $\quad$ Know how to identify a fact and dimension.

- $\quad$ Design and deploy a cube in Visual Studio.

- Demonstrate ability in rotating the cube and finding answers to several sample questions based on the AdventureWorks database.

- $\quad$ Develop students' own questions and work with a classmate to find the answers.

\section{Stimulate Recall of Prior Learning}

Immediately after the learner is informed of the objectives, the instructor should engage in a discussion related to prior learning. As previously noted, this teaching module assumes students have prior knowledge of conventional relational database principles. Students will be asked to recall and explain what they know about the relational model with regards to table design and keys. A question and answer session may be appropriate in which the instructor calls on a few students or the instructor may stimulate recall of prior learning by asking students to write down on a sheet of paper answers to some common questions. For courses with large enrollment, the use of a computer response system (e.g. i>clickers or eClicker software) may be an appropriate method for stimulating recall of prior learning.

\section{Present Stimulus Material}

The instructor should then discuss how the relational model differs from data warehousing as well as present general data warehousing terms and design principles. Following this introduction, students will be provided instructions for creating and deploying a cube. The instructor will also briefly describe the business model and implications of the AdventureWorks database. The AdventureWorks database offers a fully populated and relevant data set students can tie to real world examples.

\section{Provide Learner Guidance}

In this module students will create a new project in the Business Intelligence Studio. The process of creating and deploying the cube will be displayed on an overhead projector, providing students with both audio and visual assistance as they setup the cube. In addition, the slides (containing screenshots) and a video created using screen recording software (e.g. Camtasia Studio or CamStudio) should be posted on the course learning management system to provide additional learner guidance. Figures 2-8 highlight selected screenshots from the cube setup and deployment process. 


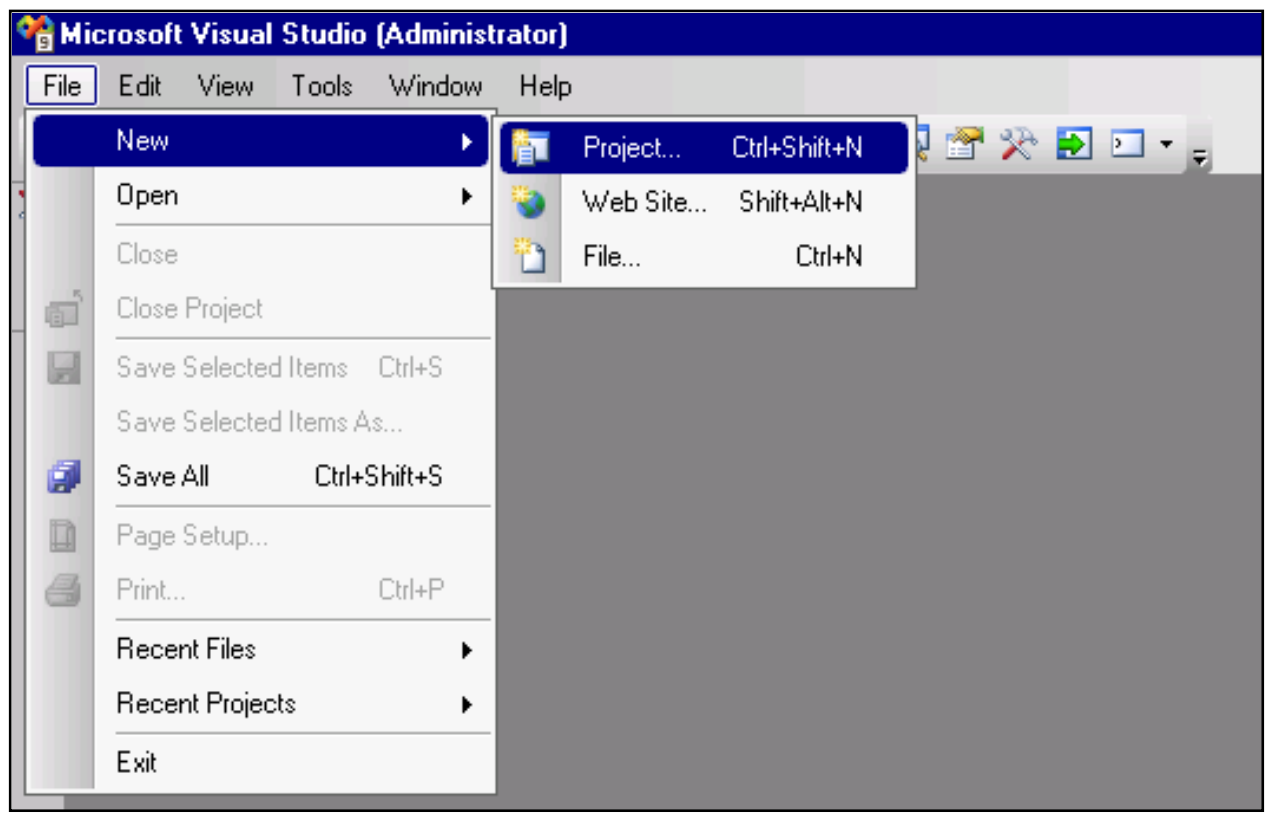

Figure 2: Create a New Project Project.

After opening the Business Intelligence Studio, students begin by creating a new project. File > New >

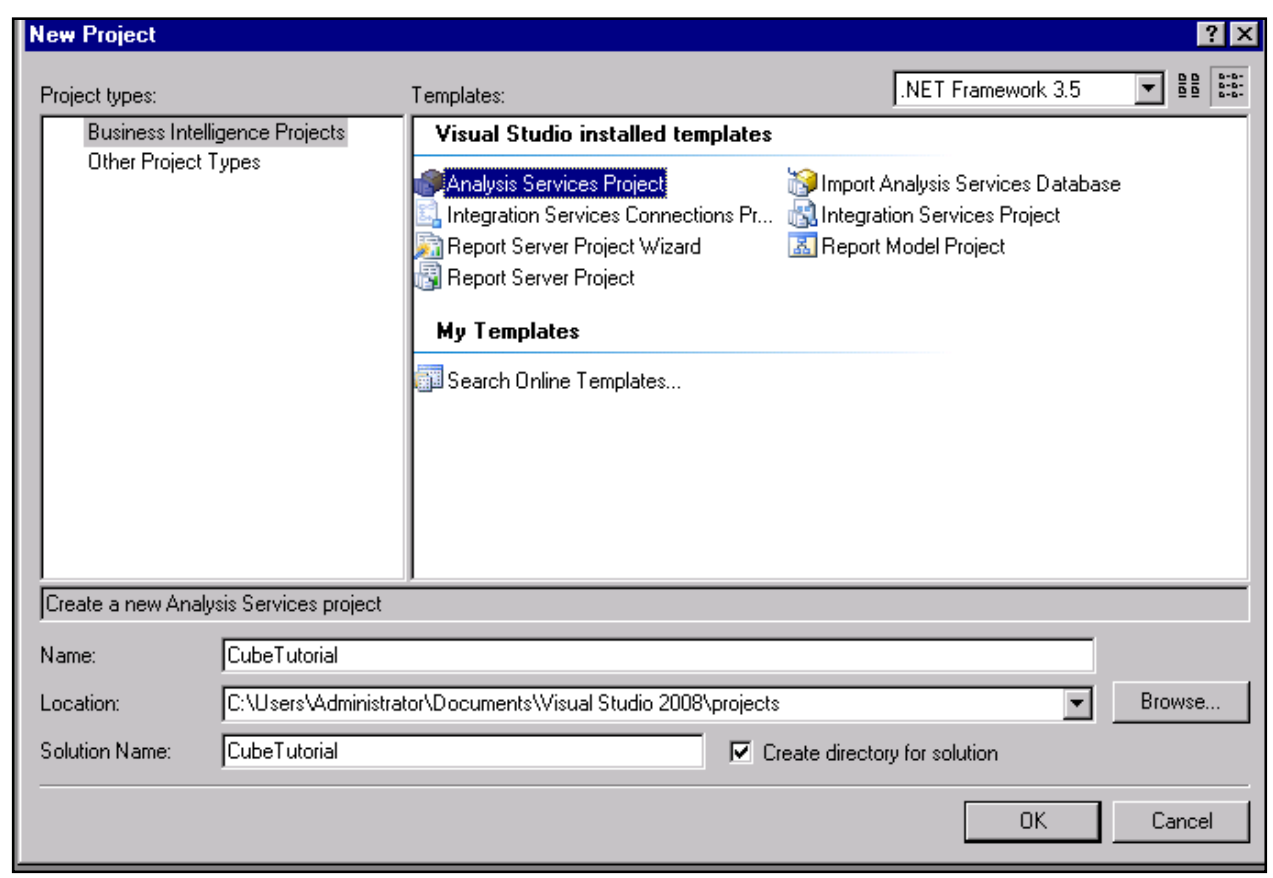

Figure 3: Create Cube and Select Project Options

Several options for projects are provided. Students choose an Analysis Services Project and provide the project a name and change the location of their project if necessary. 


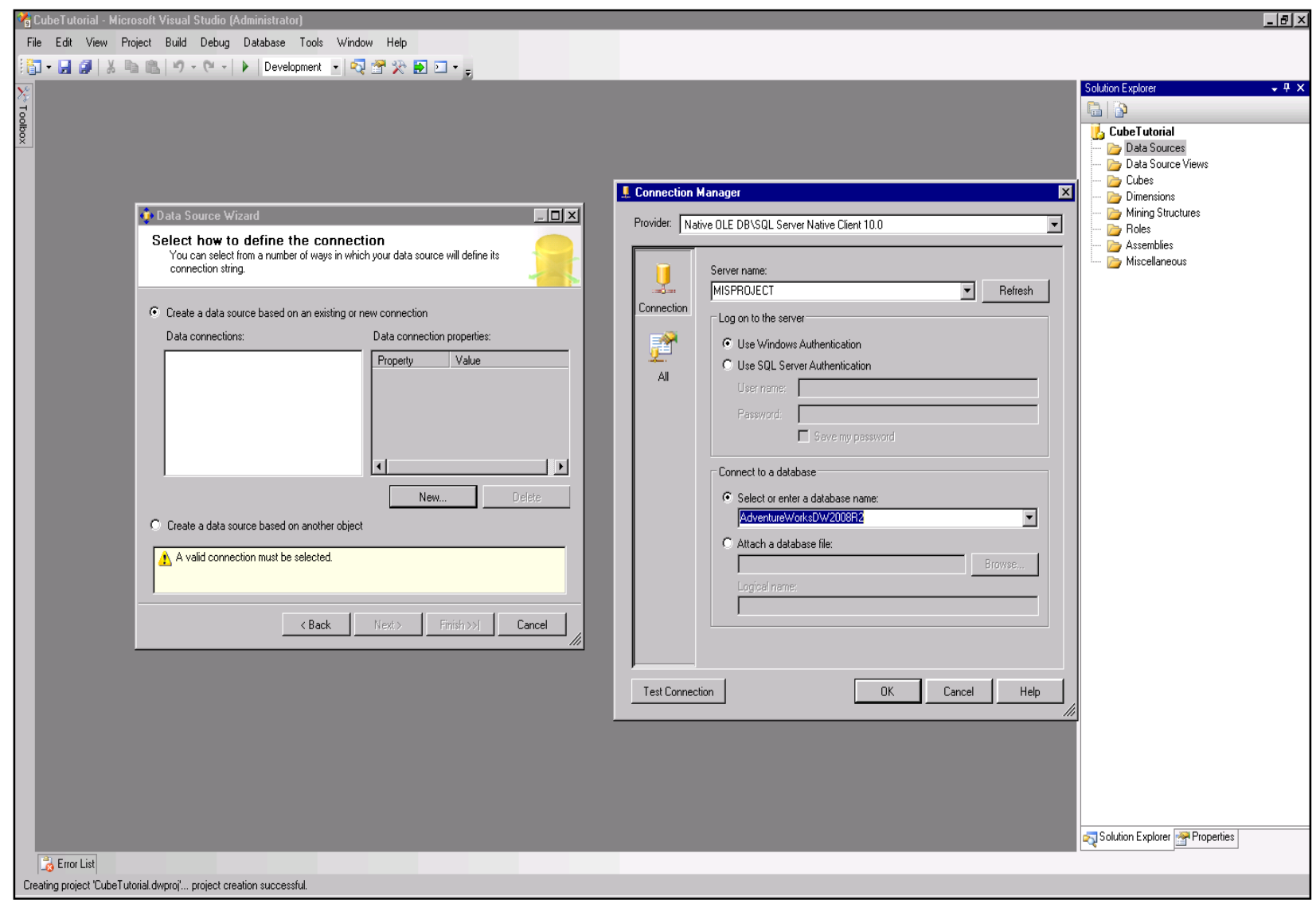

Figure 4: Define the Connection Properties to the Data Source

If there are any predefined data sources they will appear in this window. Students click on the New button to create a new data source. In the window that opens up, they define the connection properties to the database that will be the data source. Once a valid data source is selected or created, students click Next in the first window that opens up. 


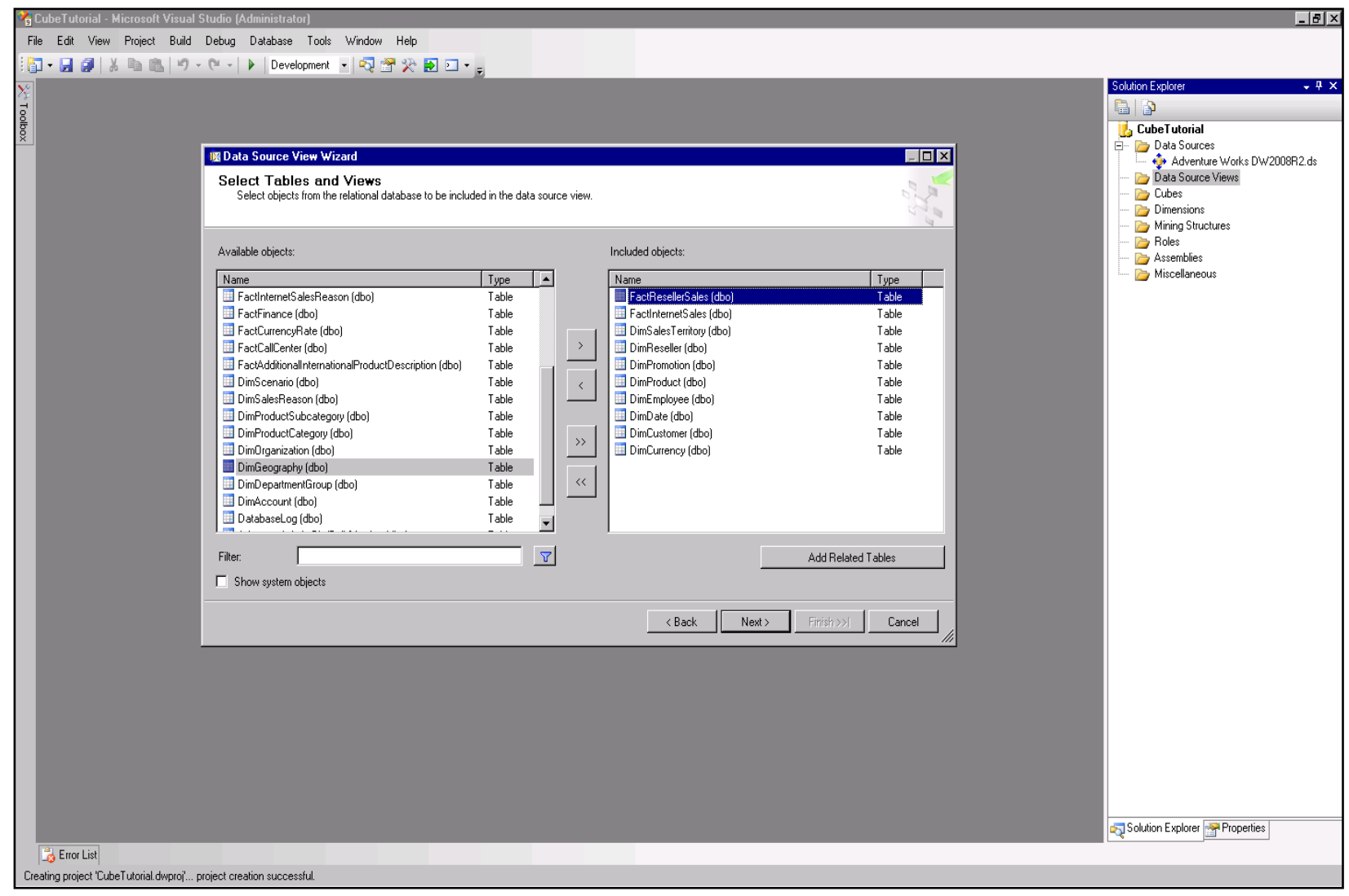

Figure 5: Select Tables

The BI Studio analyzes the data source for tables and views that can be included in the project. For this example, students select the following tables: FactResellerSales, FactInternetSales, DimSalesTerritory, DimReseller, DimPromotion, DimProduct, DimEmployee, DimDate, DimCustomer, and DimCurrency. 


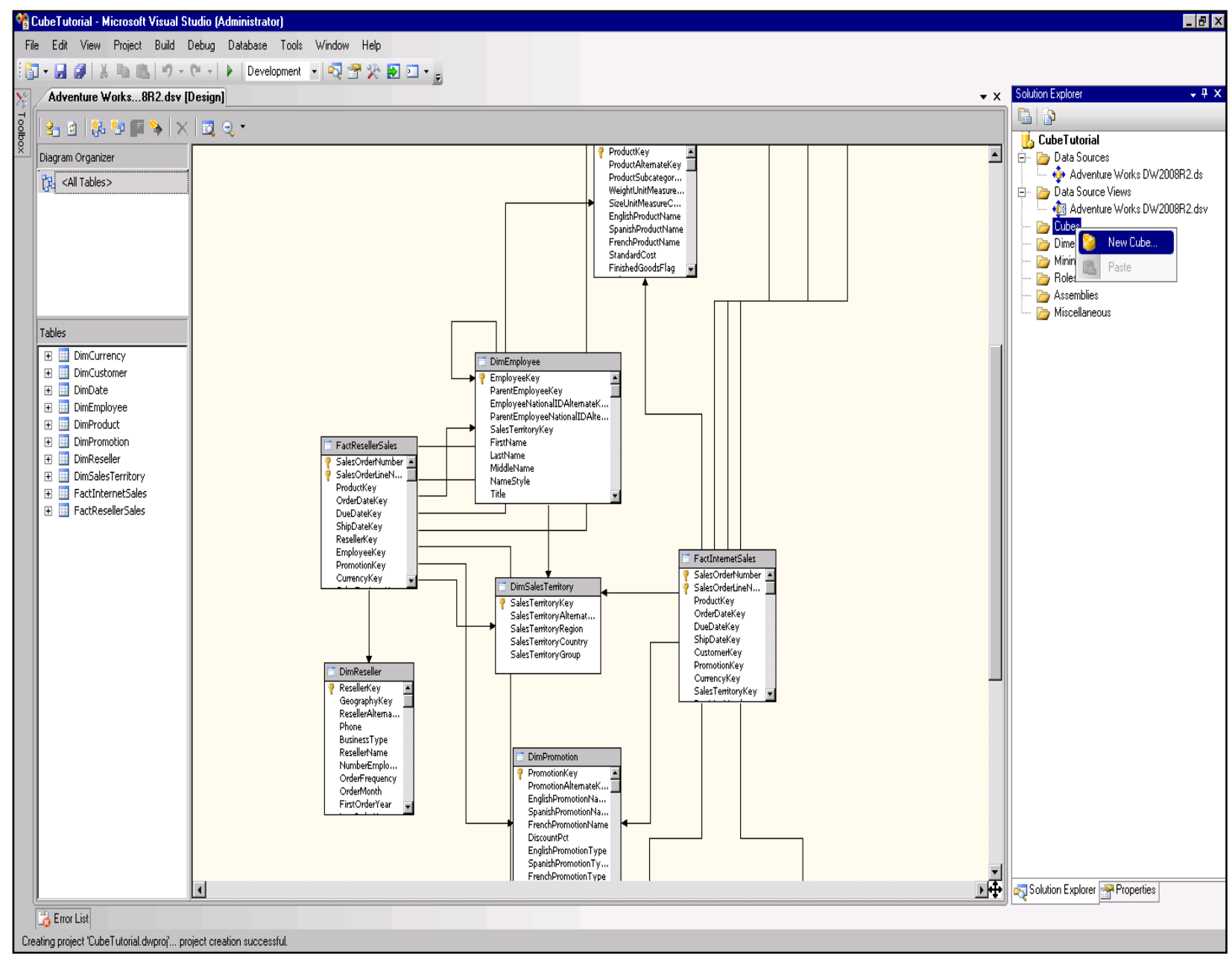

Figure 6: Define a Data Cube

With a data source and a data source view defined, students can now define a data cube. 


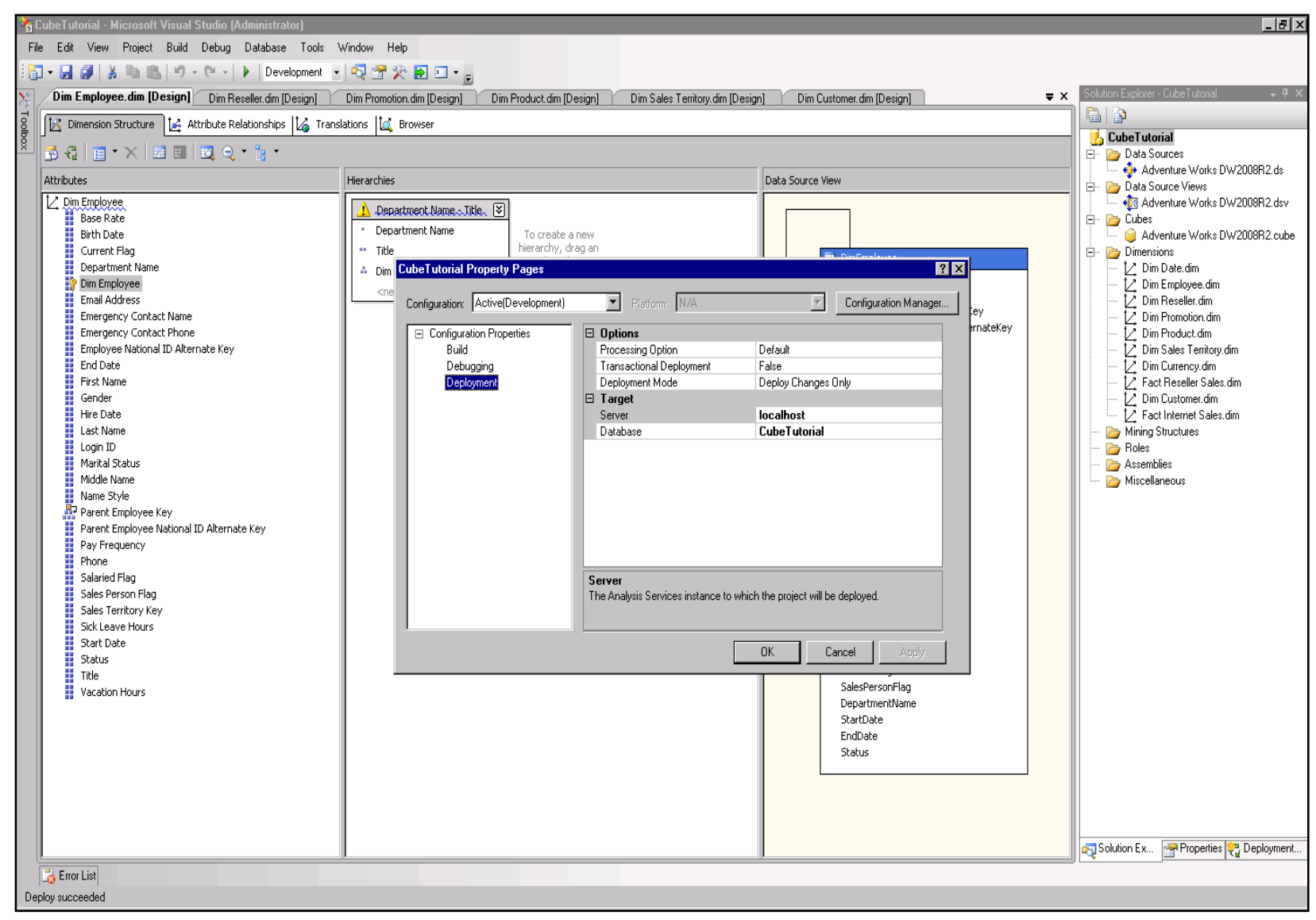

Figure 7: Deploy the Data Cube

After appropriate tables are selected, students deploy the cube. 


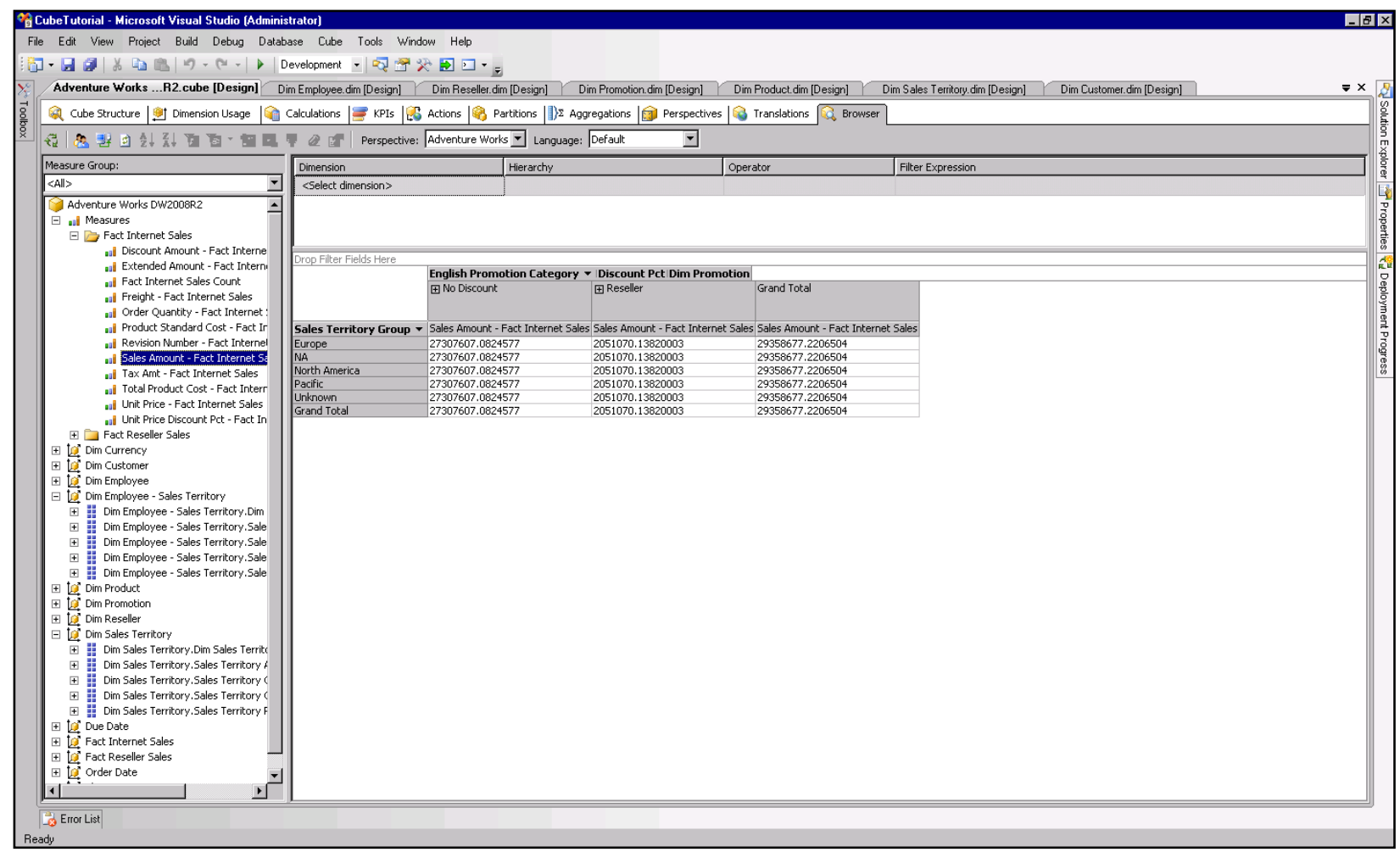

Figure 8: Open the Data Cube and Explore Options

With the cube deployed, students double click to open the cube. In this tab will be several options to explore. For example in the browse tab, students can use the pivot table view and drag a horizontal dimension, a vertical dimension, and a dimension to measure into the working pane and BI Studio will show the results of their choices.

\section{Elicit Performance}

Once the instructor has provided guidance by demonstrating the process of creating and deploying the cube, students are encouraged to practice the skills and new knowledge using realistic data. The instructor poses several relevant business questions based on the data provided. Example questions include:

- What is the sales amount for Europe area in 2010?

- $\quad$ Add another example question

- $\quad$ Add another example question

The instructor will then let the learner practice the skills and apply the knowledge. In the browser area of Analysis Services, students will try to discover the answer by dragging a fact and dimensions onto the appropriate axes.

\section{Provide Feedback}

As students practice the skills and new knowledge using realistic data based on the aforementioned questions, the instructor provides specific and immediate feedback and guidance of their individual performance as needed. The instructor should be available to answer any questions and help students solve problems they encounter while finding the answer to the questions posed. 


\section{Assess Performance}

Near the end of the business intelligence module, students should be given a short oral quiz. This assessment should be designed to test students' knowledge of topics and principles discussed to this point. This evaluation should be completed without the ability to receive additional coaching, feedback, or hints. As previously suggested, the use of a computer response system may be an appropriate method for assessing performance in larger courses.

\section{Enhance Retention Transfer}

Students should then be asked to develop their own questions based on the AdventureWorks data. The instructor will provide 5 to 10 minutes of class time for students to create their questions. After each student develops their questions they should be divided into pairs and quiz their peers. This activity is designed to help students create and apply the knowledge they have acquired to this point. The instructor will be available to answer questions and help students find desired answers.

\section{CONCLUSION}

As business intelligence continues to provide increased metrics and analytics to businesses, MIS students must become familiar with basic BI principles and implementations if they are to succeed. While there may be many reasons for the BI teaching gap at the university level, it is clear that further progress needs to be made in order to promote BI in university coursework. This paper offers an insertable module covering key competencies and principles, designed to facilitate BI teaching inclusion, benefiting both students and professors alike. The module introduced in this paper represents a preliminary venture, yet should serve as a springboard for the integration of business intelligence concepts into management information systems courses. The business intelligence teaching module should prove helpful for educators who seek to provide a practical and relevant business intelligence experience for students. Educators are encouraged to employ this module in its entirety, revise and adapt the module to coincide with their learning objectives, or explore other creative approaches for introducing BI into the MIS curriculum. Continued research and practice in this area is warranted to prepare students to make sound decisions based on the vast amount of data collected by modern corporations.

\section{AUTHOR INFORMATION}

David Olsen received his Ph.D. in Management Information Systems from The University of Arizona in 1993 and taught at The University of Akron accounting department in accounting information systems for five years. Dr. Olsen joined the MIS department at Utah State University in 1998 and teaches primarily in the database area as well as the MBA strategy and management course. His research interests include database concurrency control, accounting information systems, the integration of SQL, XML and XBRL, and database modeling. His research has been published in journals such as Communications of the ACM, Issues in Accounting Education, and the Journal of Database Management. Dr. Olsen is happiest with regards to the teaching awards he has received. E-mail: david.olsen@usu.edu. Corresponding author.

Pam Dupin-Bryant is an Associate Professor of Management Information Systems at Utah State University. She received her M.S. degree in Business Information Systems at USU and her Ph.D. in Education - Adult Learning and Technology from the University of Wyoming. Her research and scholarly writings have focused primarily on information systems pedagogy, e-learning/distance education, and business ethics. Her primary teaching activities include web design/development, business applications programming, and principles of MIS. During her 18 years at the USU Tooele Regional Campus, Dr. Dupin-Bryant has employed a wide variety of delivery methods and educational strategies to facilitate student learning. 


\section{REFERENCES}

1. Business Intelligence (BI). (2011). In BusinessDictionary.com online dictionary. Retrieved from http://www.businessdictionary.com/definition/business-intelligence-BI.html

2. Chen, H., Chiang, R. H. L, \& Storey, V. C. (2010). Business intelligence research. MIS Quarterly, 34(1), 201-203.

3. Conway, M., \& Vasseur, G. (2009). The new imperative for business schools. Business Intelligence Journal, 14(3), 13-17.

4. Gagne, R. M., Briggs, L. J., \& Wager, W. W. (1992). Principles of instructional design (4th ed.). Belmont, CA: Wadsworth/Thomson.

5. Gartner. (2006, February 7). Gartner says business intelligence software market to reach \$3 billion in 2009. Retrieved from http://www.gartner.com/press releases/asset 144782 11.html

6. IBM. (2009). The new voice of the CIO: Insights from the global chief information officer study. Retrieved from http://www-304.ibm.com/businesscenter/cpe/download0/183490/MM_CIO_Study.pdf

7. IEEE (2011). Gagne's nine events. Retrieved from https://www.ieee.org/publications standards/publications/subscriptions/prod/mdl/gagnes_nine events.html

8. Inmon, W. H., Strauss, D., \& Neushloss, G. (2008). DW 2.0: The architecture for the next generation of data warehousing. Burlington, MA: Elsevier.

9. Jourdan, Z., Rainer, R. K., \& Marshall, T. E. (2008). Business intelligence: An analysis of the literature. Information Systems Management, 25(2), 121-131.

10. Laursen, G. H. N., \& Thorlund, J. (2010). Business analytics for managers: Take business intelligence beyond reporting. Hoboken, NJ: John Wiley and Sons.

11. Liu, G. (2008). Innovating research topics in learning technology: Where are the new blue oceans? British Journal of Educational Technology, 39(4), 738-747.

12. Morris, H. et al. (2002). The financial impact of business analytics. Framingham, MA: IDC. International Data Group. Retrieved from http://www.remycorp.com/documents/IDC_ROIwpinal.pdf

13. Ranjan, J. (2008). Business justification with business intelligence. VINE, 38(4), 461 - 475.

14. Reisslein, J., Seeling, P., \& Reisslein, M. (2005). Computer-based instruction on multimedia networking fundamentals: Equational versus graphical representation. IEEE Transactions on Education, 48(3), 438447.

15. Sircar, S. (2009). Business intelligence in the business curriculum. Communications of the Association for Information Systems, 24(17), 289-302.

16. Smalltree, H. (2007). Business intelligence case study: Gartner lauds police for crime-fighting BI. Retrieved from http://searchbusinessanalytics.techtarget.com/news/1507220/ Business-intelligence-casestudy-Gartner-lauds-police-for-crime-fighting-BI

17. Turban, E., Sharda, R., Dursun, D., \& King, D. (2010). Business intelligence: A managerial approach (2nd ed.). Upper Saddle River, NJ: Pearson Prentice Hall.

18. Watson, H. J. (2008). Business schools need to change what they teach. Business Intelligence Journal, 13(4), 4-7.

19. Watson H. J., \& Wixom, B. H. (2007). The current state of business intelligence. IEEE Computer, 40(9), 96-99.

20. Wixom, B. H. (2010). The state of business intelligence in academia. Retrieved from http://www2.commerce.virginia.edu/bicongress/images/BI\%20in\%20Academia\%202009.pdf

21. $\mathrm{Xu}, \mathrm{Z}$. et al. (2005). Business intelligence - A case study in life insurance industry. IEEE International Conference on e-Business Engineering, 129-132.

22. Zhu, P., \& St. Amant, K. (2010). An application of Robert Gagné's nine events of instruction to the teaching of website localization. Journal of Technical Writing and Communication, 40(3), 337-362. 